\title{
Ursolic acid inhibits proliferation and induces apoptosis by inactivating Wnt/ $\beta$-catenin signaling in human osteosarcoma cells
}

\author{
RAN-XI ZHANG ${ }^{1,2}$, YANG LI ${ }^{1,3}$, DONG-DONG TIAN ${ }^{1,2}$, YANG LIU ${ }^{2}$, WU NIAN $^{1,2}$, XIANG ZOU $^{1,2}$, \\ QIAN-ZHAO CHEN ${ }^{1,3}$, LIN-YUN ZHOU ${ }^{1,3}$, ZHONG-LIANG DENG ${ }^{2}$ and BAI-CHENG HE ${ }^{1,3}$ \\ ${ }^{1}$ Chongqing Key Laboratory of Biochemistry and Molecular Pharmacology, Chongqing Medical University; \\ ${ }^{2}$ Department of Orthopaedics, The Second Affiliated Hospital of Chongqing Medical University; \\ ${ }^{3}$ Department of Pharmacology, School of Pharmacy, Chongqing Medical University, Chongqing, P.R. China
}

Received June 9, 2016; Accepted September 1, 2016

DOI: 10.3892/ijo.2016.3701

\begin{abstract}
Although multiple chemotherapeutic agents have been used for osteosarcoma (OS) treatment, their mechanisms need further study. Ursolic acid (UA), a pentacyclic triterpenoid, can reduce cell proliferation and induce apoptosis in various cancer cells, such as OS. However, the exact mechanism underlying this function remains unclear. In this study, we investigated the anti-proliferative effect of UA in human OS 143B cells and dissected the possible molecular mechanism underlying this effect. We demonstrated that UA can reduce cell proliferation, induce apoptosis and arrest cell cycle in 143B cells, as well as inhibit OS tumor growth in a mouse xenograft model. Using a luciferase reporter assay, we found that the $\mathrm{Wnt} / \beta$-catenin signaling is inhibited by UA in 143B cells. Correspondingly, the expression level and nuclear translocation of $\beta$-catenin are both decreased by UA. Exogenous expression of $\beta$-catenin attenuates the anticancer effect of UA in 143B cells, while knockdown of $\beta$-catenin enhances this effect. UA increases the expression level of p53 in a concentration-dependent manner, and inhibition of p53 reduces the anticancer effect of UA in 143B cells. Moreover, inhibition of p53 partly reverses the UA-induced downregulation of $\beta$-catenin, as do the targets of $\mathrm{Wnt} / \beta$-catenin signaling, such as c-Myc and cyclin D1. Our findings indicated that UA can inhibit the proliferation of 143B OS cells through inactivation of Wnt/ $\beta$-catenin signaling, which may be mediated partly by upregulating the expression of $\mathrm{p} 53$.
\end{abstract}

\section{Introduction}

Osteosarcoma (OS) is a prevalent primary malignancy of bone and mainly occurs in adolescents and children (1). OS is

Correspondence to: Professor Bai-Cheng He, Department of Pharmacology, School of Pharmacy, Chongqing Medical University, No. 1 Yixueyuan Road, Yuzhong, Chongqing 400016, P.R. China E-mail: hebaicheng99@yahoo.com; 894704897@qq.com

Key words: ursolic acid, osteosarcoma, proliferation inhibition, Wnt/ $\beta$-catenin, p53 often located in the metaphyses of long bone where it grows rapidly, including the proximal tibia, proximal humerus and distal femur $(2,3)$. OS is commonly marked by aggressive proliferation, high rate of recurrence, and early systemic metastasis, especially the metastasis to the lung (1-3). With surgery combined with the treatment of chemotherapy drugs, such as cisplatin, doxorubicin and methotrexate, a gradual improvement has been made to increase the long-term survival rate (4). However, the current therapeutic regimen remains undesirable and often results in chemoresistance (5). Hence, there is an urgent clinical need to explore new antitumor reagents for OS. The traditional Chinese medicine, especially the herb-derived components, has received increasing attention as a source of novel pharmacologics. Better curative effects have been noted when herb-derived components are combined with the traditional chemotherapy agents in treatment for multiple cancers (6-8).

Ursolic acid (UA), one of these potential compounds, is a pentacyclic triterpenoid. It has been identified in medical herbs and edible plants, including loquat leaf and rosemary. Previous studies have revealed that UA can suppress proliferation and induce apoptosis in various tumor cells, such as prostate, lung and pancreas $(6,9,10)$. Furthermore, UA has been reported to be able to inhibit tumor progression (11), induce tumor cell differentiation (12) and inhibit angiogenic activity (13). UA was also found to be chemopreventive in different animal models $(13,14)$, suppress tumor invasion $(10)$, and sensitize the orthotopically implanted pancreatic tumors to gemcitabine (6). It has been confirmed that UA can modulate various cancer-related signals. For example, UA interferes with DNA replication (15), activates caspases (16) and c-Jun N-terminal kinases (JNK) (7), downregulates anti-apoptotic genes, such as COX-2, NO synthase and protein tyrosine kinase (15). UA has been shown to increase the expression of p53, while decreasing that of $\mathrm{NF}-\kappa \mathrm{B}$, and this effect was differentiated in tumor cells as compared to normal cells, which did not exhibit this response to UA (17). Moreover, UA was found to induce cell cycle arrest at G1 phase in tumor cells (18). Recently, it was reported that UA was effective in inducing apoptosis of MG-63 OS in vitro (19). However, the exact mechanism underlying these effects of UA in OS remains unknown. 
It has been verified that $\mathrm{Wnt} / \beta$-catenin signaling is a pivotal factor in modulating proliferation, differentiation and motility of cells (20). Aberrant activation of $\mathrm{Wnt} / \beta$-catenin signaling was found in a number of bone tumors $(21,22)$. Former studies indicated that several ligands, receptors and co-receptors of Wnt maintain high expression levels in OS cells, whereas Wnt inhibitors are decreased $(23,24)$. Therefore, a number of novel antitumor strategies for OS have been developed by targeting the Wnt/ $\beta$-catenin signaling (22). Although UA shows valid antitumor activities in a variety of tumors, it still remains unclear whether the mechanism underlying the antitumor activity of UA on OS cells is implicated with the inhibition of $\mathrm{Wnt} / \beta$-catenin signaling.

In the present study, we evaluated the inhibitory effect of UA on the proliferation of human OS cells, and dissected the possible mechanisms underlying these effects. We found that UA could inhibit the proliferation and induce apoptosis in 143B OS cells. The inhibitory effect of UA may be mediated by inactivating Wnt/ $\beta$-catenin signaling through upregulating p53 at least.

\section{Materials and methods}

Chemical preparations and cell lines. UA, with a purity of 98.6\%, was obtained from Xi'an Hao-Xuan Bio-Tech Co., Ltd. (Xi'an, China). The human OS cell line 143B was obtained from the American Type Culture Collection (Manassas, VA, USA). Pifithrin- $\alpha$ (PFT- $\alpha$ ) was purchased from Selleck Chemicals (Houston, TX, USA). UA and PFT- $\alpha$ were dissolved with dimethyl sulfoxide (DMSO) for experiments in vitro. For in vivo experiments, UA was suspended in $0.4 \%$ carboxymethylcellulose sodium. The primary antibodies rabbit anti-human STAT3 and p-STAT3 were obtained from Abcam (Cambridge, MA, USA), and other antibodies were obtained from Santa Cruz Biotechnology, Inc. (Dallas, TX, USA). Cells were cultured with DMEM (containing 10\% FBS, $100 \mathrm{U} / \mathrm{ml}$ of penicillin and $100 \mu \mathrm{g} / \mathrm{ml}$ of streptomycin). Cells were incubated in $5 \% \mathrm{CO}_{2}$ and $37^{\circ} \mathrm{C}$.

Cell viability assay. Cell viability was determined with Cell Counting Kit-8 (CCK-8). In brief, 143B cells were seeded in 96 -well plates with a final density of $3 \times 10^{3}$ cells/well and incubated for $24 \mathrm{~h}$. The cells were treated with different concentrations of UA, recombinant adenovirus or DMSO for 24, 48 and $72 \mathrm{~h}$. Thereafter, $10 \mu \mathrm{l}$ of CCK-8 (Dojindo Laboratories, Kumamoto, Japan) were added into each well and incubated for another $4 \mathrm{~h}$. The absorbance was determined at $450 \mathrm{~nm}$ with a microplate reader. Each test was conducted in triplicate.

Clonogenic assay. The clonogenic assay was employed to determine the ability of cells in a given population to undergo unlimited division and form colonies. This assay was carried out as described (25). Briefly, cells were treated with different concentrations of UA for $24 \mathrm{~h}$ and then replated with 2,000 cells/well into 6-well plates. Then cells were maintained up to 14 days until colonies were formed. Plates were washed gently with PBS and incubated with $0.25 \%$ crystal violet formalin solution at room temperature for $20 \mathrm{~min}$. Each test was conducted in triplicate.
Flow cytometric analysis for cell cycle and apoptosis. The 143B cells were plated into a 6-well plate. For cell cycle assay, cells were treated with different concentrations of UA or DMSO for $24 \mathrm{~h}$. Then cells were harvested, washed with cold $\left(4^{\circ} \mathrm{C}\right) \mathrm{PBS}$, fixed with cold $\left(4^{\circ} \mathrm{C}\right) 70 \%$ ethanol. Finally, cells were suspended in $300 \mu \mathrm{l} \mathrm{PBS}$, and incubated with propidium iodide (PI) $(20 \mathrm{mg} / \mathrm{ml})$ and RNase $(1 \mathrm{mg} / \mathrm{ml})$ for $30 \mathrm{~min}$. The cells were detected with fluorescence-activated cell sorting (FACS) subsequently. The DNA contents were analyzed with ModFit LT software. For apoptosis analysis, cells were treated with UA for $24 \mathrm{~h}$. Then the cells were collected and washed with cold $\left(4^{\circ} \mathrm{C}\right) \mathrm{PBS}$, incubated with Annexin V-FITC/PI following the instruction of the kits (KeyGen, Nanjing, China). Finally, the processed cells were sorted with FACS and the data were analyzed with FlowJo. Each test was conducted in triplicate.

Construction of recombinant adenoviruses. Recombinant adenoviruses expressing $\beta$-catenin (AdBC) and small interfering RNA fragments targeting $\beta$-catenin (AdsiBC) were constructed with AdEasy system (26), respectively. AdBC was tagged with green fluorescence protein and AdsiBC was tagged with red fluorescence protein. The adenovirus-expressing green fluorescence protein (AdGFP) only was used as vector control.

Western blotting. Subconfluent 143B cells were plated in a 6-well plate and treated with pre-designated concentrations of UA or DMSO. For total cellular protein or tissue protein, cells and tissues were harvested and lysed using ice-cold lysis buffer at pre-designated time-points. For subcellular fractionation, the protein was extracted with NE-PER ${ }^{\mathrm{TM}}$ Nuclear and Cytoplasmic Extraction Reagents (Pierce Biotechnology, Inc., Rockford, IL, USA) based on the manufacturer's instructions. The lysates were boiled for $10 \mathrm{~min}$, subjected to SDS-PAGE separation and transferred to polyvinylidene difluoride (PVDF) membranes. Then the membranes were blotted with corresponding primary antibodies, followed by incubation with HRP-labelled second antibodies. Finally, the bands of target proteins were developed with the SuperSignal West Pico Substrate (Pierce Biotechnology, Inc.). All assays were performed in triplicate.

Reverse transcription-polymerase chain reaction ( $R T-P C R)$ analysis. Cells were treated with indicated concentrations of UA in T-25 culture flasks. Total RNA was extracted with TRIzol reagents (Invitrogen, Carlsbad, CA, USA) and transcribed to cDNA templates with RT reaction at pre-designated time-points. Then, the cDNA templates were used to detect the expression levels of target genes by PCR. The primer sequences are available upon request. All assays were performed in triplicate.

Luciferase reporter assay. Cells were seeded in T-25 culture flasks and transfected with $\beta$-catenin/TCF-4 luciferase reporter (pTOP-luc) $3 \mu \mathrm{g}$ per flask with Lipofectamine 2000 (Invitrogen) $(25,27)$. The cells were replated into a 24 -well plate $16 \mathrm{~h}$ after transfection, and then treated with indicated concentrations of UA or DMSO. The cell lysates were subjected to luciferase assays with luciferase assay kit (Promega Corp., 

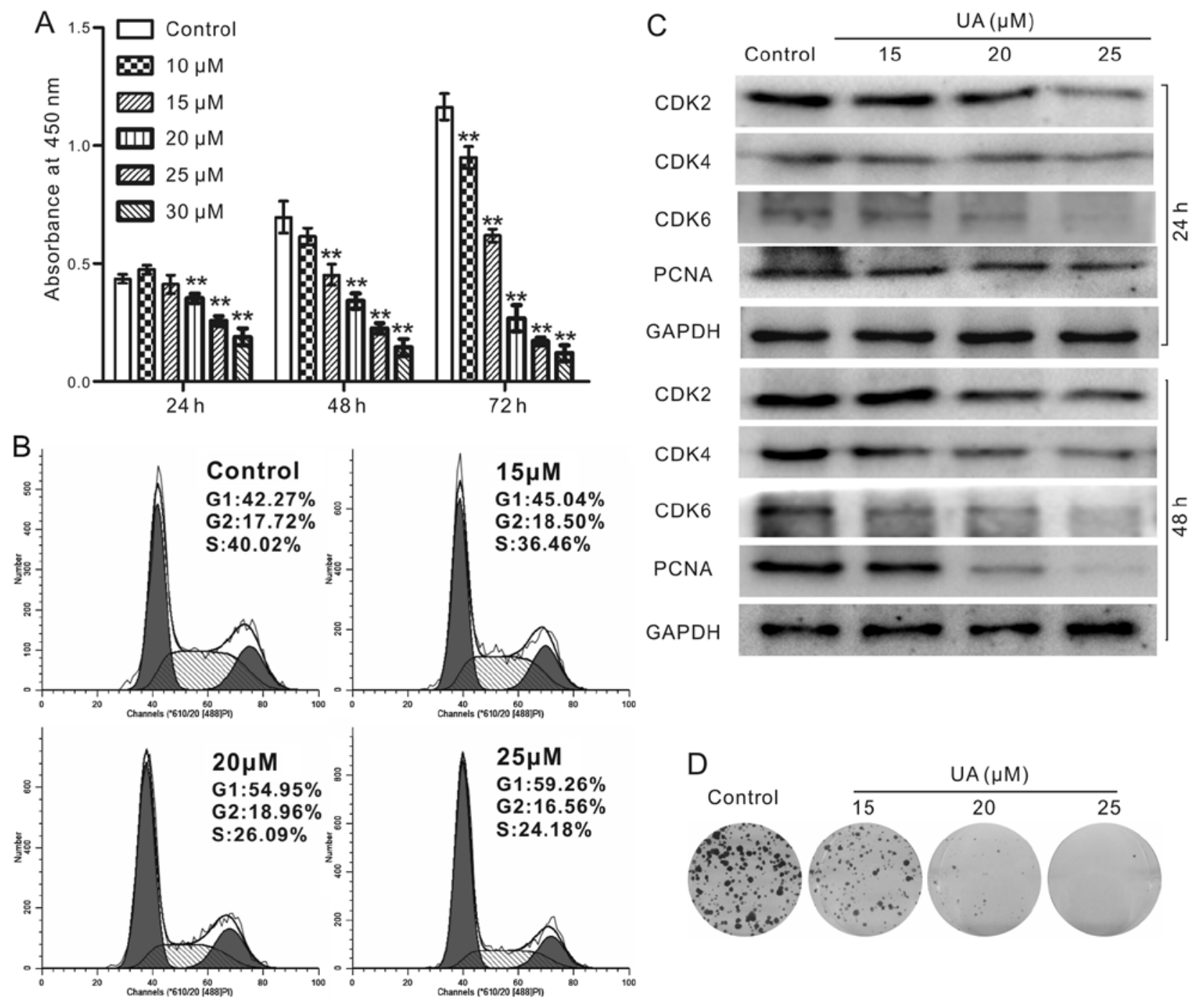

Figure 1. Effects of UA on cell proliferation in human OS cells. (A) The results of CCK-8 assays show the anti-proliferative effect of UA in 143B cells ( $"$ p $<0.01$ vs. control). (B) Cell cycle analyses show G1 phase arrest of 143B cells induced by UA. (C) Western blotting results indicate the protein levels of CDK2, CDK4, CDK6 and PCNA affected by UA. GAPDH was used as loading control. (D) The clonogenic assay of 143B cells shows the effect of UA on colony formation. All assays were performed in triplicate. UA, ursolic acid; OS, osteosarcoma; CCK-8, Cell Counting Kit-8; CDK2, cyclin-dependent kinase 2; PCNA, proliferating cell nuclear antigen.

Madison, WI, USA) $24 \mathrm{~h}$ after treatment. All assays were performed in triplicate.

Xenograft model of human OS. The animal experiment was approved by the Institutional Animal Care and Use Committee (IACUC) of Chongqing Medical University. Athymic nude mice (female, 4-6 weeks old, 5/group) were from the Animal Center of Chongqing Medical University (Chongqing, China). The 143B cells were collected and re-suspended in cold PBS $\left(4^{\circ} \mathrm{C}\right)$ to $2 \times 10^{7}$ cells $/ \mathrm{ml}$. Then cells in $100 \mu 1$ of PBS were injected subcutaneously into the right flanks of the nude mice. Three days after injection, the athymic nude mice were given UA (100 and $200 \mathrm{mg} / \mathrm{kg}$ ) or solvent by intragastric administration once a day for 4 weeks. The mice were sacrificed and the tumor samples were photographed and harvested for histological evaluation.

Immunohistochemical staining and histological evaluation. Retrieved tumor masses were fixed with $4 \%$ paraformaldehyde and embedded with paraffin, respectively. Serial sections were deparaffinized and rehydrated in a gradient fashion. Then the slides were stained with hematoxylin and eosin (H\&E) (25). For immunohistochemical staining, the slides were further processed for antigen retrieval, and incubated with proliferating cell nuclear antigen (PCNA) antibody (1:100 dilution), or Wnt/ $\beta$-catenin antibody (1:50 dilution) or isotype IgG as control. Finally, the slides were incubated with streptavidin-labelled secondary antibodies and visualized with 3,3'-diaminobenzidine (DAB) tetrahydrochloride reagent $(25,27)$.

Statistical analysis. All quantitative tests were performed in triplicate. Statistical analyses were performed with GraphPad Prism 5 (GraphPad Software, Inc., La Jolla, CA, USA). All measurement results were expressed as mean \pm SD. Statistical significances between the two groups were determined with Student's t-test. $p<0.05$ was considered statistically significant. 
A
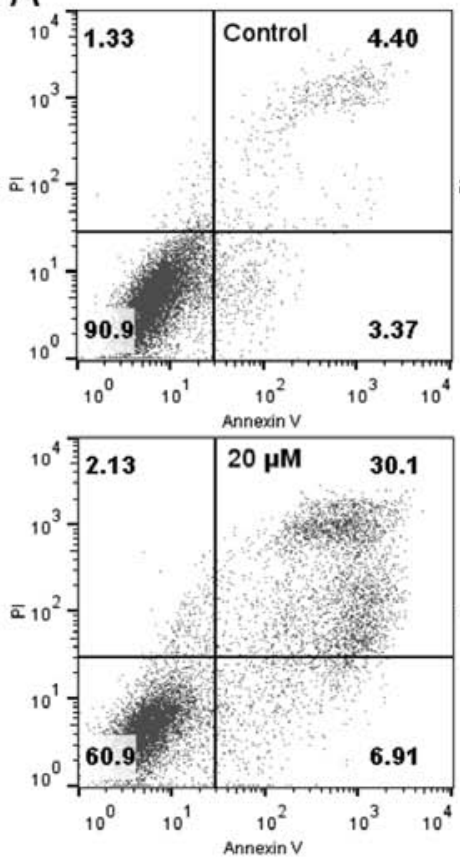
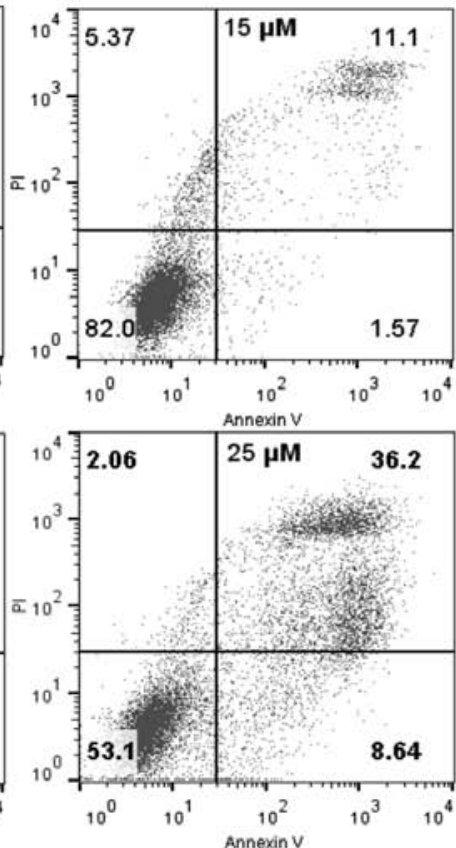

B

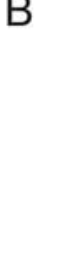

\begin{tabular}{lcc} 
UA $(\mu \mathrm{M})$ \\
\hline 15 & 20 & 25
\end{tabular}

Cleaved
caspase-3
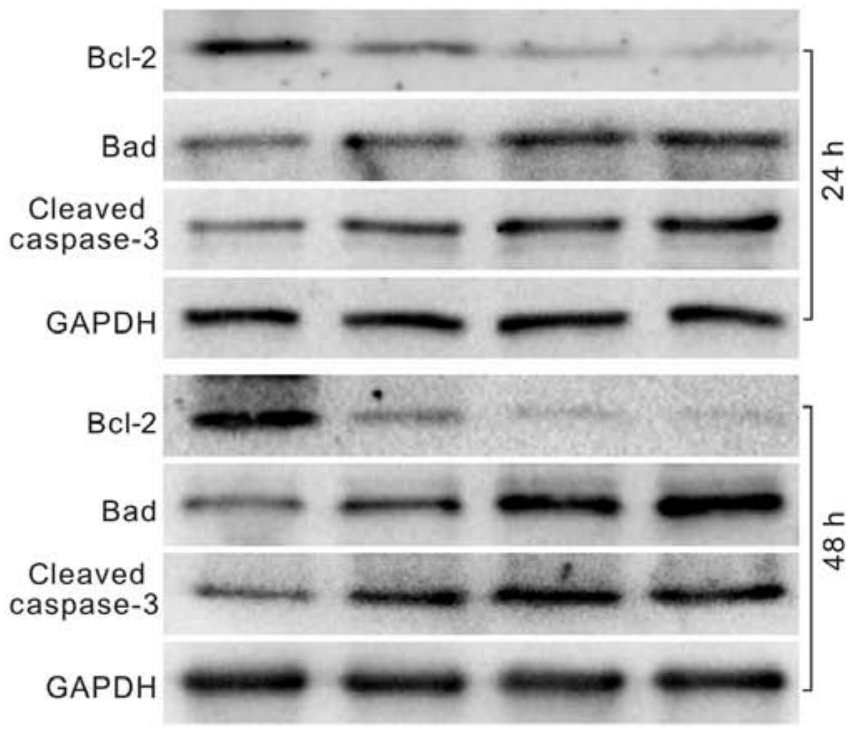

Figure 2. Effects of UA on apoptosis in human OS cells. (A) Flow cytometric analyses show apoptosis of 143B cells induced by UA. (B) Western blotting results show the expression of cleaved caspase-3, Bad and Bcl-2 in 143B cells. GAPDH was used as loading control. All assays were performed in triplicate. UA, ursolic acid; OS, osteosarcoma.

\section{Results}

UA inhibits cell proliferation in $143 \mathrm{~B}$ cells. To identify whether UA may serve as an effective chemotherapeutic reagent for human OS, the CCK-8 assay was employed to validate the anti-proliferative effect of UA in 143B cells. We found that the proliferation of 143B cells can be inhibited markedly by UA in a time- and concentration-dependent manner (Fig. 1A). Cell cycle analyses indicated that UA induces cell cycle arrest at G1 phase in 143B cells (Fig. 1B). We further checked the biomarkers of G1 arrest. The results indicated that UA inhibited the expression of cyclin-dependent kinase 2 (CDK2), CDK4 and CDK6 (Fig. 1C). Moreover, UA effectively suppresses the protein level of PCNA (Fig. 1C), an indicator for the status of proliferation (28). We further checked whether UA can affect the long-term colony formation ability in human OS cells. Our results illustrated that UA concentration-dependently inhibits the colony formation in 143B cells (Fig. 1D). The above results showed that UA is capable of inhibiting cell proliferation in 143B cells.

UA induces apoptosis in $143 \mathrm{~B}$ cells. Next, we determined whether apoptosis occurs in human OS cells with the treatment of UA. 143B cells were treated with different concentrations of UA for 24 or $48 \mathrm{~h}$. Then cells were analyzed with flow cytometric assay or lysed for western blotting. The results showed that UA can increase the apoptotic cell rate (Fig. 2A), enhance the protein level of Bad and cleaved caspase- 3 , and reduces the level of Bcl-2 concentration-dependently (Fig. 2B). According to the above results, UA can induce apoptosis in OS cells.

UA inhibits the growth of OS tumor in nude mice. We next assessed the antitumor activity of UA in vivo with a well-estab- lished xenograft OS model (27). The results showed that tumor masses in UA-treated group are smaller than those in control group, and UA inhibits the tumor growth significantly compared with control group (Fig. 3A and B). Subsequently, histologic assay was conducted to evaluate the xenograft samples. H\&E staining results revealed that more necrotic cells occur in UA-treated groups than that of the control group (Fig. 3C). Furthermore, the expression of PCNA was markedly decreased in UA-treated groups (Fig. 3D), which was consistent with our data in vitro. In addition, we evaluated tumor tissue at molecular level and found that p53 was strongly elevated by UA, while $\beta$-catenin, NF- $\kappa B$ and the phosphorylation of STAT3 were decreased (Fig. 3E). These data implied that UA may suppress the growth of OS via $\beta$-catenin and inflammatory signaling. Collectively, these in vivo results supported that UA may be a potential antitumor reagent for human OS.

UA suppresses Wnt/ $\beta$-catenin signaling in $143 B$ cells. Cell proliferation is well regulated by multiple signaling pathways. With luciferase reporter assay, we found that the transcriptional activity of $\beta$-catenin/TCF-4 reporter was effectively reduced by UA (Fig. 4A). Given that the stabilization and nuclear translocation of $\beta$-catenin are critical events in the activation of $\mathrm{Wnt} / \beta$-catenin signaling (27), we employed western blotting assay to check whether UA can decrease the level of $\beta$-catenin in the whole cell, cytoplasm, and nucleus. The results indicated that UA decreases the protein level of $\beta$-catenin not only in the nucleus, but also in the cytoplasm and the whole cells (Fig. 4B). Moreover, we checked the level of downstream targets in Wnt/ $\beta$-catenin signaling. The results showed that the expression of c-Myc and cyclin D1 were both decreased by UA concentration-dependently (Fig. 4C). The immunohistochemical results showed 

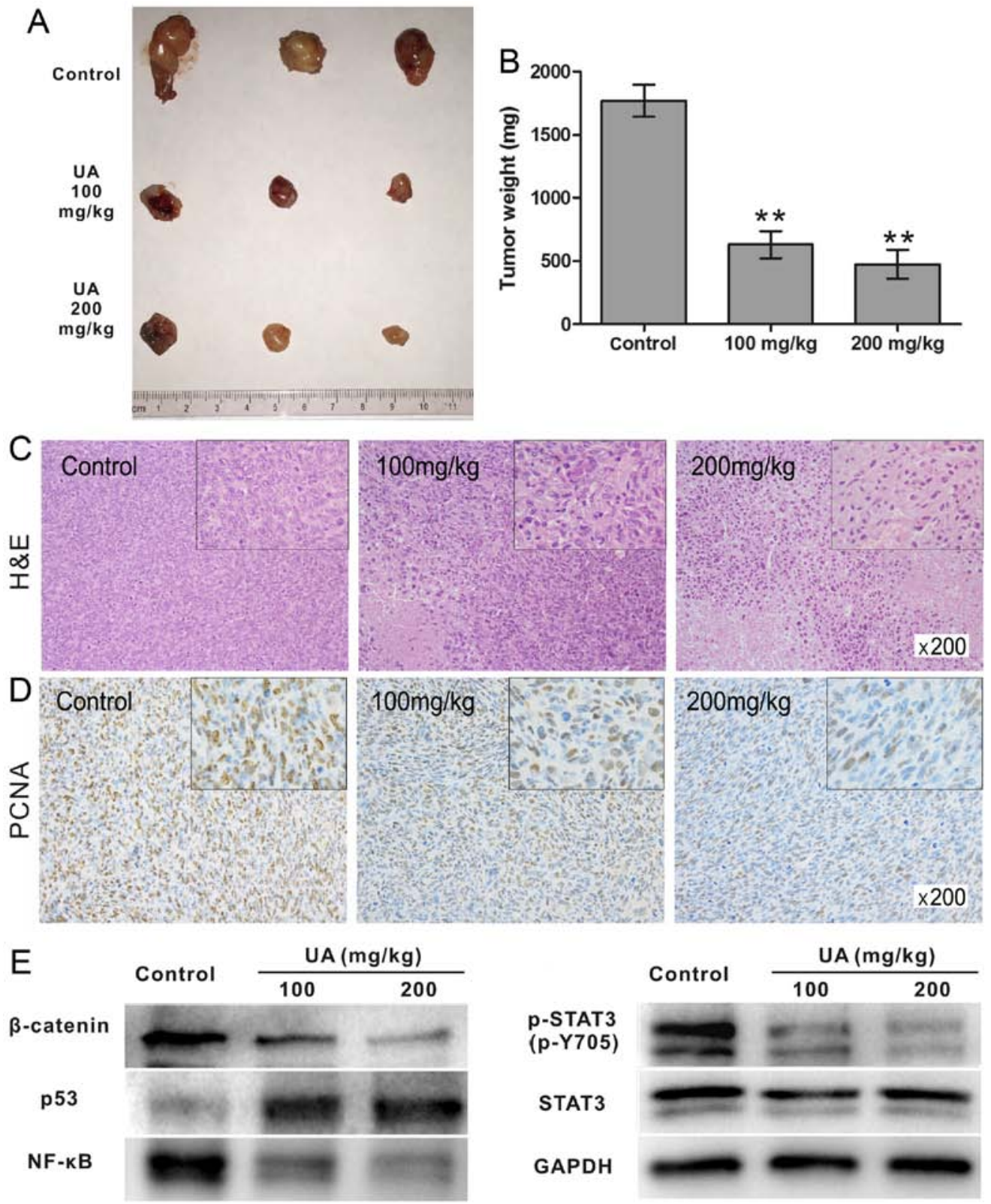

Figure 3. Effects of UA on tumor growth in human OS xenograft model. (A) Tumor masses retrieved from nude mice show antitumor effect of UA on OS xenograft. (B) Weight of tumor mass shows the antitumor effect of UA on OS xenograft (** $p<0.01$ vs. control). (C) H\&E staining results show the antitumor effect of UA in human OS. (D) Immunohistochemical staining results show the expression of PCNA in UA-treated OS tumors. The upper rectangles show the detail of each panel at $x 400$. Representative results are shown. The target proteins stained brown and the cell nuclei stained blue. (E) Western blotting results show the expression of $\beta$-catenin, p53, NF- $\mathrm{kB}$, STAT3 and p-STAT3 in OS tissues. GAPDH was used as loading control. UA, ursolic acid; OS, osteosarcoma; H\&E, hematoxylin and eosin; PCNA, proliferating cell nuclear antigen.

that $\beta$-catenin positive cells were reduced with UA treatment dose-dependently (Fig. 4D). These results suggested that the anti-proliferative effects of UA in OS cells may be associated with the suppression of $\mathrm{Wnt} / \beta$-catenin signaling.

Wnt/ $\beta$-catenin partly mediates the anti-proliferative effect of $U A$ in $143 B$ cells. To investigate the role of $\mathrm{Wnt} / \beta$-catenin signaling in the anti-proliferative effect of UA in 143B cells, we employed recombinant adenovirus to mediate the exogenous expression or knockdown for $\beta$-catenin. With CCK-8 assay, we found that exogenous expression of $\beta$-catenin attenuated the anti-proliferative effects of UA, while knockdown of $\beta$-catenin enhanced this function of UA in 143B cells (Fig. 5A). FACS analysis results indicated that overexpression of $\beta$-catenin attenuated the G1 phase arrest induced by UA in 143B cells. On the contrary, $\beta$-catenin knockdown augmented UA-induced G1 phase arrest (Fig. 5B). Thus, our data indicated that UA may exert its antitumor effects in OS cells by partly inactivating $\mathrm{Wnt} / \beta$-catenin signaling.

UA inactivates Wnt/ $\beta$-catenin signaling through upregulating p53 in $143 B$ cells. Although inactivation of $\mathrm{Wnt} / \beta$-catenin signaling partly mediates the anti-proliferative effects of UA in 143B cells, the mechanism on how UA regulates Wnt/ $\beta$-catenin signaling remains unknown. With further research, we discovered that UA upregulated the mRNA level 


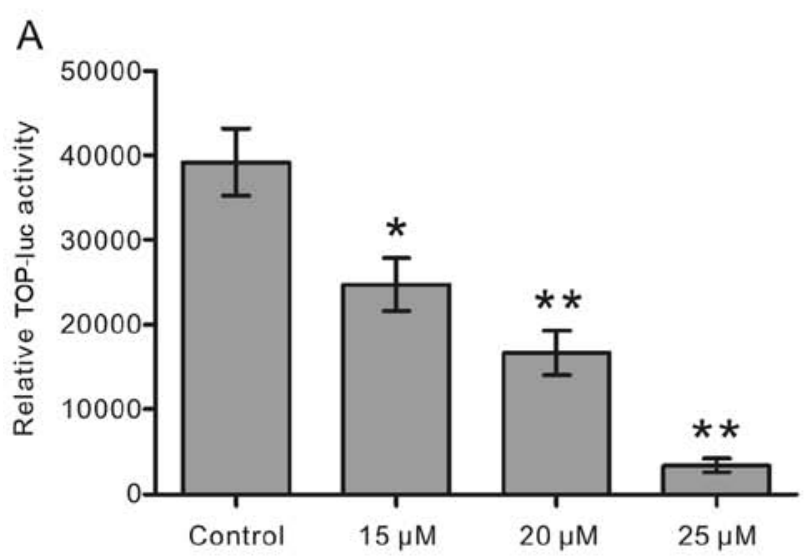

B

B
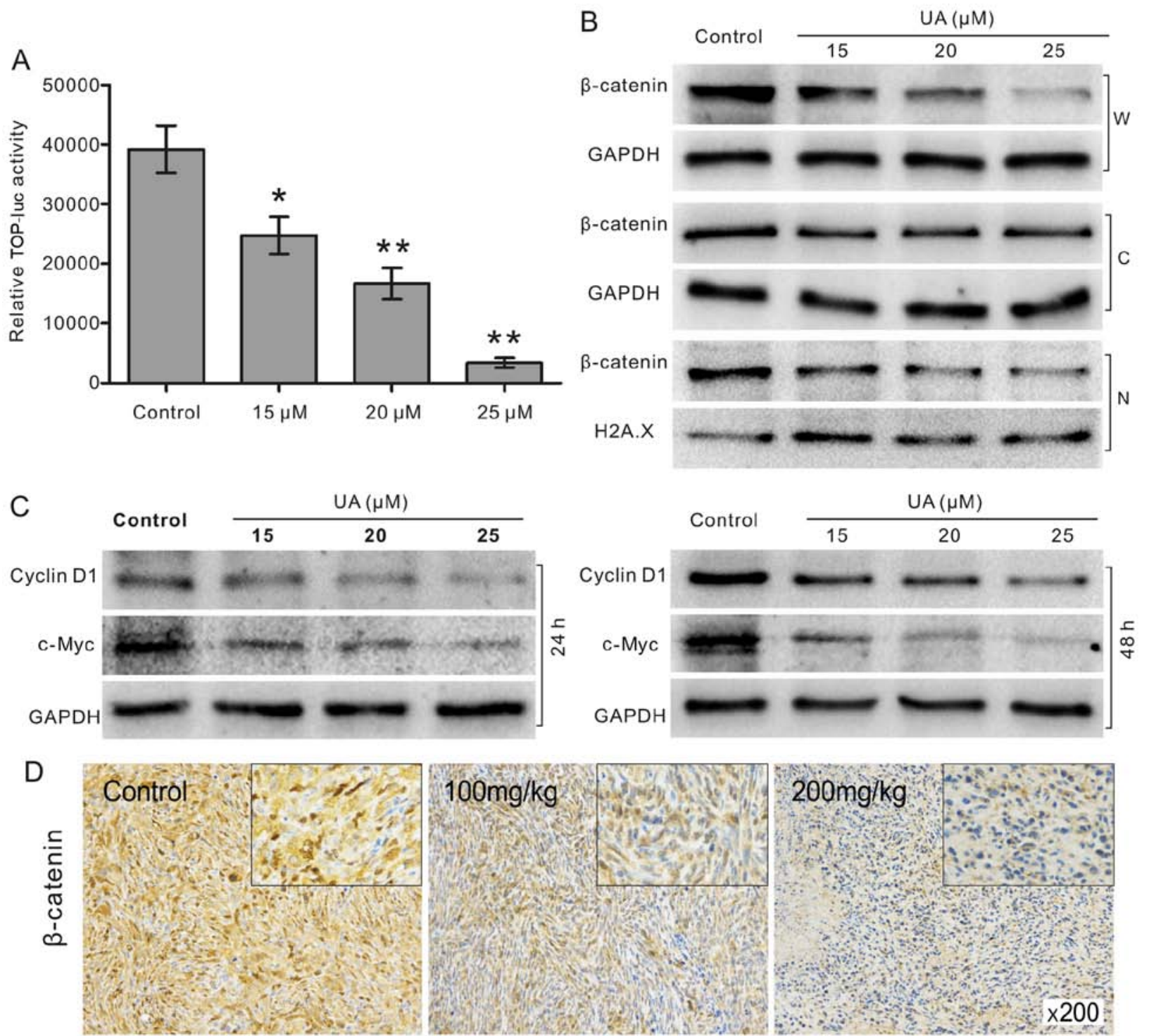

Figure 4. Effects of UA on Wnt/ $\beta$-catenin signaling in OS cells. (A) The result of luciferase reporter assay shows the effect of UA on $\beta$-catenin/TCF transcription activity ( ${ }^{*} \mathrm{p}<0.05$ vs. control; ${ }^{* *} \mathrm{p}<0.01$ vs. control). (B) Western blotting results show the effect of UA on the protein expression of $\beta$-catenin in the whole cell, cytoplasm and nucleus (W, whole cell; C, cytoplasm; N, nucleus). GAPDH was used as loading control. (C) Western blotting results show the effect of UA on the expressions of cyclin D1 and c-Myc in 143B cells. GAPDH was used as loading control. (D) Immunohistochemical staining results show the expression of $\beta$-catenin in UA-treated OS tumors. The upper rectangles show the detail of each panel at $\mathrm{x} 400$. Representative results are shown. The target proteins stained brown and the cell nuclei stained blue. UA, ursolic acid; OS, osteosarcoma.

of p53 (Fig. 6A), increased the protein expression level of p53 and reduced the expression of MDM2 time- and concentration-dependently (Fig. 6B). A previous study demonstrated that overexpression of p53 downregulates $\beta$-catenin in human and mouse cells (29). Therefore, we hypothesized that UA-induced inactivation of $\mathrm{Wnt} / \beta$-catenin signaling may be mediated through the activation of $\mathrm{p} 53$. With western blotting assay, we found that the effects of UA on $\beta$-catenin, c-Myc and cyclin D1 were partly reversed by p53 inhibitor (PFT- $\alpha$ ) (Fig. 6C). Furthermore, the results of CCK-8 assay also showed that PFT- $\alpha$ can partly attenuate the anti-proliferative effects of UA in 143B cells (Fig. 6D), which is similar with the effects of exogenous expression of $\beta$-catenin on anti-proliferative effects of UA (Fig. 5A). Our data suggested that the inactivation of $\mathrm{Wnt} / \beta$-catenin signaling induced by UA may be mediated by upregulating p53 in OS cells.

\section{Discussion}

In this study, we demonstrated that UA may be a potential anti-proliferative drug for OS cells in vivo and in vitro. Mechanistically, we discovered that the anticancer activities of UA may be partly mediated by suppression of $\mathrm{Wnt} / \beta$-catenin signaling through upregulating p53 at least.

$\mathrm{OS}$ is one of the common malignants, which accounts for the primary OS-induced mortalities. Although surgical and medical advances have been made during the past decades, the overall survival rate of patients with OS remains 60-65\% (30). The present drugs used for OS chemotherapy are mainly the same as that used in 1980s, such as doxorubicin, etoposide, cisplatin, ifosfamide and high-dose methotrexate (31). Therefore, it is urgent to explore more efficient drugs or treatment regiments for OS. 

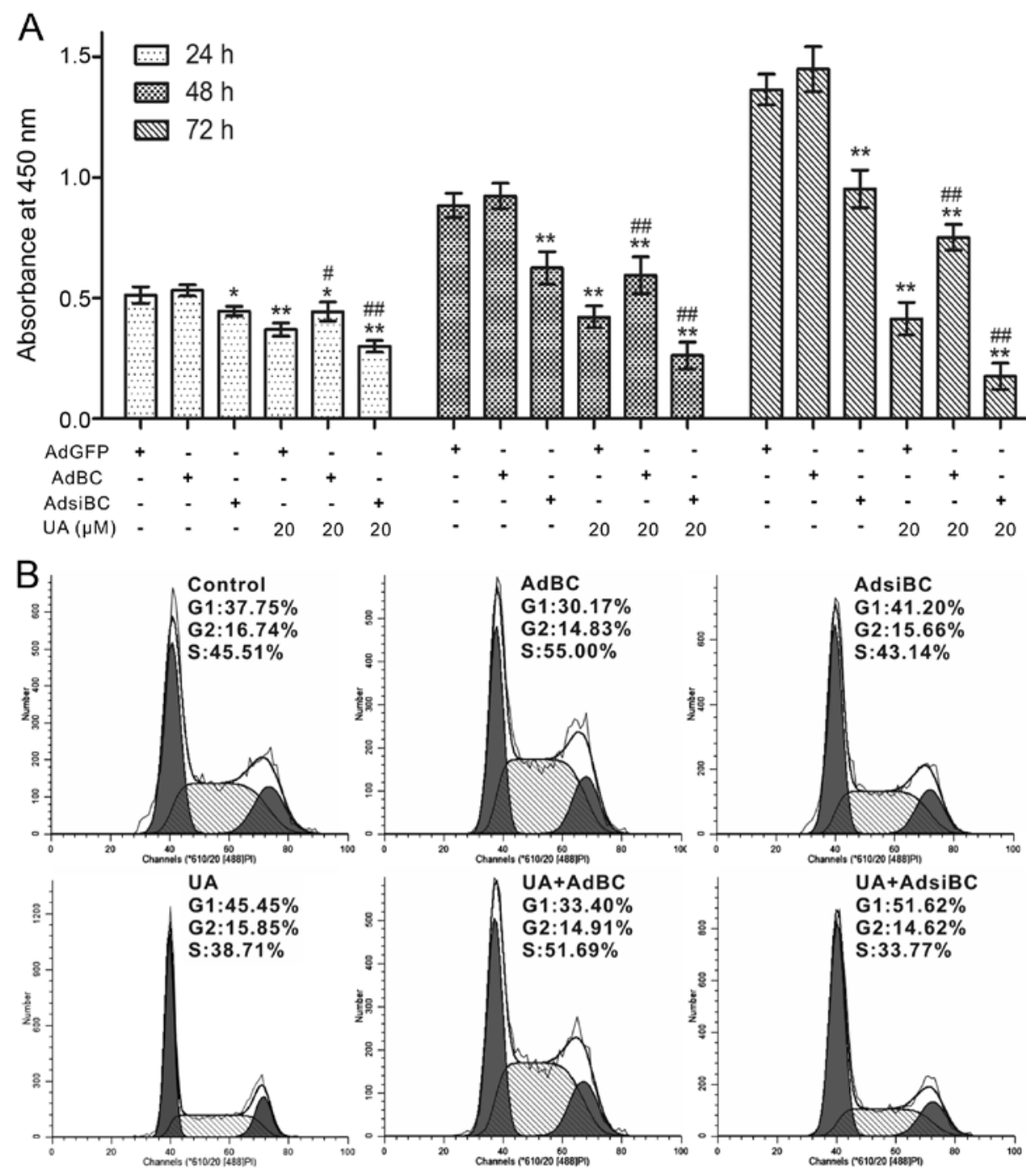

Figure 5. Effects of $\beta$-catenin on the antitumor activity of UA in OS cells. (A) The results of CCK- 8 assays show the effect of $\beta$-catenin in UA-induced anti-proliferation of $143 \mathrm{~B}$ cells ( $" \mathrm{p}<0.05$ vs. control; ${ }^{* *} \mathrm{p}<0.01 \mathrm{vs}$. control; ${ }^{*} \mathrm{p}<0.05 \mathrm{vs}$. UA; ${ }^{\# \#} \mathrm{p}<0.01 \mathrm{vs.} \mathrm{UA)}$ ). (B) Flow cytometric analyses show the effects of $\beta$-catenin on UA-induced G1 phase arrest in 143B cells. All assays were performed in triplicate. UA, ursolic acid; OS, osteosarcoma; CCK-8, Cell Counting Kit-8.

Herb-derived component is becoming increasingly important in tumor therapies. For example, curcumin, sinomenine and oldenlandia were all identified to be effective anti-osteosarcoma drugs (32-34). UA was identified in wax coating of apples 100 years ago. Nowadays, UA can be extracted from many medical herbs and edible plants (35). It shows multiple pharmacological functions, such as inhibition of tumor progression, induction of cell differentiation, inhibition of angiogenic activity and control of oxidants (35). For cancer, it has been documented that UA can induce apoptosis in prostatic cancer cells (36), inhibit the proliferation of pancreatic cancer, increase the antitumor potential of gemcitabine (6), inhibit colorectal cancer angiogenesis (13), and chemoprevent the genesis, metastasis and invasion of tumor in different animal models $(10,14)$. Recently, it was reported that UA was effective in inducing apoptosis in MG-63 OS in vitro (19). Accordingly, our data also showed that UA inhibits proliferation time- and concentration-dependently in 143B OS cells (Fig. 1); in addition, UA also induces apoptosis in 143B cells by activating caspase- 3 and modulating the proteins associated with survival, such as Bad and Bcl-2 (Fig. 2). With further analysis, we proved that UA is able to inhibit the growth of OS tumor in vivo (Fig. 3). This evidence supported the conclusion that UA may be a promising natural compound for tumor therapy, such as OS at least.

As reported, UA is a multi-target natural product (37), the antitumor effects of UA may be mediated by inactivating Wnt/ $\beta$-catenin, PI3K/Akt, MAPK and NF- $\kappa B$ signaling $(12,38,39)$. Considering OS, the anticancer activity of UA may be associated with upregulating caspase and activating ERK, JNK, and p38 MAPK signaling (19). However, the exact mechanism underlying the antitumor effects of UA in OS still remains unclear. Wnt/ $\beta$-catenin signaling is involved in the processes of maintenance of homeostasis and development by regulating cell proliferation, differentiation, migration and apoptosis, as well as keeping stem cells under pluripotent state (40). The aberrant activation of $\mathrm{Wnt} / \beta$-catenin signaling was implicated with tumorigenic, metastasis and invasion of a variety of cancers (41), including OS. When Wnt/ $/$-catenin signaling is activated, $\beta$-catenin accumulates in the cytoplasm 

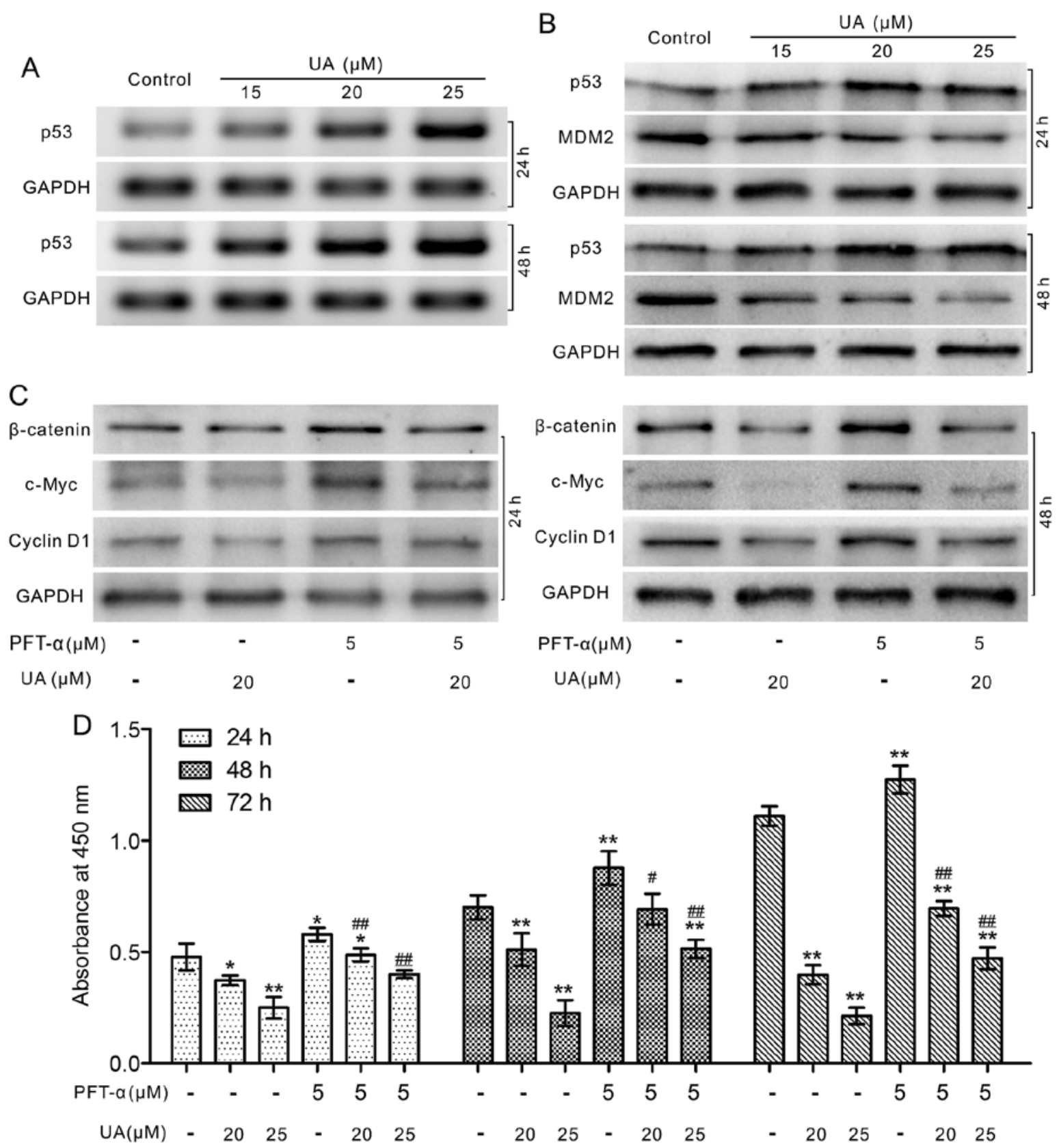

Figure 6. Effects of p53 on UA-induced inhibition of Wnt/ $/$-catenin in OS cells. (A) PCR analysis results show the mRNA expression of p53 in UA-treated 143B cells. GAPDH was used as loading control. (B) Western blotting results show the effect of UA on p53 and MDM2 in 143B cells. GAPDH was used as loading control. (C) Western blotting results show the effects of p53 inhibitor (PFT- $\alpha$ ) on UA-induced decrease of $\beta$-catenin, cyclin D1 and c-Myc. GAPDH was used as loading control. (D) The results of CCK-8 assay show the effect of p53 inhibitor on UA-induced anti-proliferation in 143B cells ("p $<0.05$ vs. control; ${ }^{* *} \mathrm{p}<0.01 \mathrm{vs}$. control; ${ }^{\#} \mathrm{p}<0.05$ vs. the group treated with equal UA; ${ }^{\# \#} \mathrm{p}<0.01$ vs. the group treated with equal UA). All assays were performed in triplicate. UA, ursolic acid; OS, osteosarcoma; PFT- $\alpha$, pifithrin- $\alpha$; CCK-8, Cell Counting Kit-8.

and then translocates into the nucleus, where it regulates the expression of downstream target genes to regulate the growth and survival of cells (22). Therefore, many antitumor drugs target $\mathrm{Wnt} / \beta$-catenin signaling $(27,42,43)$. A previous study has proved that accumulation of $\beta$-catenin in nuclear and/or cytoplasm occurred in OS cells, and the accumulation may be associated with the pathogenesis of OS (44). As Wnt/ $\beta$-catenin signaling is a target of UA, we speculated that the anticancer activity of UA in 143B cells may be also associated with it. In the present study, we found that UA can inhibit the transcriptional activity of pTOP-luc reporter in 143B cells (Fig. 4A), as well as the expression of $\beta$-catenin in cytoplasm and nucleus in vitro and in vivo (Fig. $4 \mathrm{~B}$ and $\mathrm{D}$ ). It is noteworthy that $\mathrm{c}-\mathrm{Myc}$ and cyclin D1 are downstream targets of Wnt/ $\beta$-catenin (45). We found that UA can reduce the expression of $\mathrm{c}-\mathrm{Myc}$ and cyclin D1 (Fig. 4C). All this evidence indicates that UA can inhibit Wnt/ $\beta$-catenin signaling in 143B OS cells. Our results further demonstrated that exogenous expression of $\beta$-catenin attenuates the effects of anti-proliferation and cell cycle arrest induced by UA in 143B cells, while knockdown of $\beta$-catenin enhances these functions of UA (Fig. 5). Thus, the antitumor activities of UA in 143B OS cells may be mediated by inactivating Wnt/ $\beta$-catenin signaling, but this finding alone does not reveal how $\mathrm{Wnt} / \beta$-catenin signaling is modulated and thus 
additional experiments need to be conducted to elucidate the inhibitory mechanism.

p53, a well-known tumor suppressor, is a cell cycle regulator with a transient half-life (46). The function of p53 is regulated by enhancing its transcription and post-translational stabilization to escape ubiquitin-dependent degradation (47). An earlier study reported that UA can induce apoptosis in SW480 cells by increasing p53 (48). Moreover, Wnt/ $\beta$-catenin signaling can be downregulated by p53 $(29,49)$. To make sure that p53 is involved in the UA-induced cell growth inhibition and apoptosis, we analyzed the effect of UA on the expression level of p53 in 143B cells. The results showed that both mRNA and protein level of p53 are increased by UA (Fig. 6A and B). Although Wnt/ $\beta$-catenin signaling is tightly modulated by the Axin/APC/GSK3 $\beta$ complex (50), the level of $\beta$-catenin can also be negatively regulated by p53 $(29,49)$. Furthermore, the downregulation of $\beta$-catenin induced by p53 was accompanied with the inhibition of its transcription potential (49). So we employed PFT- $\alpha$, a p53 inhibitor, to determine whether p53 mediates the inhibition of Wnt $/ \beta$-catenin signaling induced by UA. PFT- $\alpha$ was verified to effectively enhance the expression of $\beta$-catenin in gastric adenocarcinoma cells (51). However, a converse observation that PFT- $\alpha$ decreases the protein level of $\beta$-catenin in WB-F344 cells was reported in another study (52). These findings suggested that the effects of PFT- $\alpha$ on $\beta$-catenin may be cell type-specific. Our results indicated that PFT- $\alpha$ can effectively upregulate the expression of $\beta$-catenin, as well as the targets of $\mathrm{Wnt} / \beta$-catenin signaling in $143 \mathrm{~B}$ OS cells (Fig. 6C). We further analyzed the effect of p53 inactivation by PFT- $\alpha$ on cell proliferation in 143B OS cells, and found that PFT- $\alpha$ promotes the growth of 143B cells and attenuates the anti-proliferative effects of UA. Hence, the inhibitory effects of UA on Wnt/ $\beta$-catenin signaling may be mediated by upregulating p53 partly in 143B cells.

Taken together, our data suggested that UA can be used as an effective chemotherapy agent for human OS. The antitumor activity of UA on OS may be mediated by inactivating Wnt/ $\beta$-catenin signaling through upregulating p53. However, the exact molecular mechanisms through which UA upregulates p53 need to be further investigated.

\section{Acknowledgements}

We thank Dr Tong-Chuan He (University of Chicago, IL, USA) for providing recombinant adenoviruses and pTOP-luc plasmid. This study was supported by a research grant from the National Natural Science Foundation of China (grant nos. NSFC 81372120 and 81572226 to Bai-Cheng He).

\section{References}

1. Cheng S, Zhang X, Huang N, Qiu Q, Jin Y and Jiang D Down-regulation of S100A9 inhibits osteosarcoma cell growth through inactivating MAPK and NF- $\kappa \mathrm{B}$ signaling pathways. BMC Cancer 16: 253-253, 2016.

2. Bielack SS, Kempf-Bielack B, Delling G, Exner GU, Flege S, Helmke K, Kotz R, Salzer-Kuntschik M, Werner M, Winkelmann W, et al: Prognostic factors in high-grade osteosarcoma of the extremities or trunk: An analysis of 1,702 patients treated on neoadjuvant cooperative osteosarcoma study group protocols. J Clin Oncol 20: 776-790, 2002.
3. Kempf-Bielack B, Bielack SS, Jürgens H, Branscheid D, Berdel WE, Exner GU, Göbel U, Helmke K, Jundt G, Kabisch H, et al: Osteosarcoma relapse after combined modality therapy: An analysis of unselected patients in the Cooperative Osteosarcoma Study Group (COSS). J Clin Oncol 23: 559-568, 2005.

4. Ando K, Heymann M-F, Stresing V, Mori K, Rédini F and Heymann D: Current therapeutic strategies and novel approaches in osteosarcoma. Cancers (Basel) 5: 591-616, 2013.

5. Chou AJ and Gorlick R: Chemotherapy resistance in osteosarcoma: Current challenges and future directions. Expert Rev Anticancer Ther 6: 1075-1085, 2006.

6. Prasad S, Yadav VR, Sung B, Gupta SC, Tyagi AK and Aggarwal BB: Ursolic acid inhibits the growth of human pancreatic cancer and enhances the antitumor potential of gemcitabine in an orthotopic mouse model through suppression of the inflammatory microenvironment. Oncotarget 7: 13182-13196, 2016.

7. Pu F, Chen F, Lin S, Chen S, Zhang Z, Wang B and Shao Z: The synergistic anticancer effect of cisplatin combined with Oldenlandia diffusa in osteosarcoma MG-63 cell line in vitro. Onco Targets Ther 9: 255-263, 2016.

8. Chen S, Wang Z, Huang Y, O'Barr SA, Wong RA, Yeung S and Chow MSS: Ginseng and anticancer drug combination to improve cancer chemotherapy: A critical review. Evid Based Complement Alternat Med 2014: 168940, 2014.

9. Zhang Y, Kong C, Zeng Y, Wang L, Li Z, Wang H, Xu C and Sun Y: Ursolic acid induces PC-3 cell apoptosis via activation of JNK and inhibition of Akt pathways in vitro. Mol Carcinog 49: 374-385, 2010.

10. Huang CY, Lin CY, Tsai CW and Yin MC: Inhibition of cell proliferation, invasion and migration by ursolic acid in human lung cancer cell lines. Toxicol In Vitro 25: 1274-1280, 2011.

11. Shanmugam MK, Ong TH, Kumar AP, Lun CK, Ho PC, Wong PTH, Hui KM and Sethi G: Ursolic acid inhibits the initiation, progression of prostate cancer and prolongs the survival of TRAMP mice by modulating pro-inflammatory pathways. PLoS One 7: e32476, 2012.

12. Deng L, Zhang R, Tang F, Li C, Xing Y-Y and Xi T: Ursolic acid induces U937 cells differentiation by PI3K/Akt pathway activation. Chin J Nat Med 12: 15-19, 2014.

13. Lin J, Chen Y, Wei L, Hong Z, Sferra TJ and Peng J: Ursolic acid inhibits colorectal cancer angiogenesis through suppression of multiple signaling pathways. Int J Oncol 43: 1666-1674, 2013.

14. Gayathri R, Priya DKD, Gunassekaran GR and Sakthisekaran D: Ursolic acid attenuates oxidative stress-mediated hepatocellular carcinoma induction by diethylnitrosamine in male Wistar rats. Asian Pac J Cancer Prev 10: 933-938, 2009.

15. Choi BM, Park R, Pae HO, Yoo JC, Kim YC, Jun CD, Jung BH, Oh GS, So HS, Kim YM, et al: Cyclic adenosine monophosphate inhibits ursolic acid-induced apoptosis via activation of protein kinase A in human leukaemic HL-60 cells. Pharmacol Toxicol 86: 53-58, 2000.

16. Harmand PO, Duval R, Delage C and Simon A: Ursolic acid induces apoptosis through mitochondrial intrinsic pathway and caspase-3 activation in M4Beu melanoma cells. Int J Cancer 114: $1-11,2005$.

17. Lee YH, Kumar NC and Glickman RD: Modulation of photochemical damage in normal and malignant cells by naturally occurring compounds. Photochem Photobiol 88: 1385-1395, 2012

18. Lee YH, Wang E, Kumar N and Glickman RD: Ursolic acid differentially modulates apoptosis in skin melanoma and retinal pigment epithelial cells exposed to UV-VIS broadband radiation. Apoptosis 19: 816-828, 2014.

19. Wu CC, Cheng CH, Lee YH, Chang IL, Chen HY, Hsieh CP and Chueh PJ: Ursolic acid triggers apoptosis in human osteosarcoma cells via caspase activation and the ERK1/2 MAPK pathway. J Agric Food Chem 64: 4220-4226, 2016.

20. Behrens J and Lustig B: The Wnt connection to tumorigenesis. Int J Dev Biol 48: 477-487, 2004

21. Chen C, Zhao M, Tian A, Zhang X, Yao Z and Ma X: Aberrant activation of $\mathrm{Wnt} / \beta$-catenin signaling drives proliferation of bone sarcoma cells. Oncotarget 6: 17570-17583, 2015.

22. Tian J, He H and Lei G: Wnt/ $/$-catenin pathway in bone cancers. Tumour Biol 35: 9439-9445, 2014.

23. Hoang BH, Kubo T, Healey JH, Sowers R, Mazza B, Yang R, Huvos AG, Meyers PA and Gorlick R: Expression of LDL receptor-related protein 5 (LRP5) as a novel marker for disease progression in high-grade osteosarcoma. Int J Cancer 109: 106-111, 2004 
24. Kansara M, Tsang M, Kodjabachian L, Sims NA, Trivett MK Ehrich M, Dobrovic A, Slavin J, Choong PF, Simmons PJ, et al: Wnt inhibitory factor 1 is epigenetically silenced in human osteosarcoma, and targeted disruption accelerates osteosarcomagenesis in mice. J Clin Invest 119: 837-851, 2009.

25. He BC, Gao JL, Luo X, Luo J, Shen J, Wang L, Zhou Q, Wang YT, Luu HH, Haydon RC, et al: Ginsenoside Rg3 inhibits colorectal tumor growth through the downregulation of Wnt/B-catenin signaling. Int J Oncol 38: 437-445, 2011.

26. Luo J, Deng ZL, Luo X, Tang N, Song WX, Chen J, Sharff KA, Luu HH, Haydon RC, Kinzler KW, et al: A protocol for rapid generation of recombinant adenoviruses using the AdEasy system. Nat Protoc 2: 1236-1247, 2007.

27. Liu Y, Liu YZ, Zhang RX, Wang X, Meng ZJ, Huang J, Wu K, Luo JY, Zuo GW, Chen L, et al: Oridonin inhibits the proliferation of human osteosarcoma cells by suppressing Wnt/ $\beta$-catenin signaling. Int J Oncol 45: 795-803, 2014.

28. Park HR and Park YK: Expression of p53 protein, PCNA, and Ki-67 in osteosarcomas of bone. J Korean Med Sci 10: 360-367, 1995.

29. Sadot E, Geiger B, Oren M and Ben-Ze'ev A: Down-regulation of beta-catenin by activated p53. Mol Cell Biol 21: 6768-6781,2001.

30. Serra M and Hattinger CM: The pharmacogenomics of osteosarcoma. Pharmacogenomics J: May 31, 2016 (Epub ahead of print).

31. Hattinger CM, Fanelli M, Tavanti E, Vella S, Ferrari S, Picci P and Serra M: Advances in emerging drugs for osteosarcoma. Expert Opin Emerg Drugs 20: 495-514, 2015.

32. Chen P, Wang H, Yang F, Chen H, He W and Wang J: Curcumin promotes osteosarcoma cell death by activating miR-125a/ERRo signal pathway. J Cell Biochem: May 27, 2016 (Epub ahead of print).

33. Siegel HJ and Pressey JG: Current concepts on the surgical and medical management of osteosarcoma. Expert Rev Anticancer Ther 8: 1257-1269, 2008.

34. Xie T, Ren HY, Lin HQ, Mao JP, Zhu T, Wang SD and Ye ZM: Sinomenine prevents metastasis of human osteosarcoma cells via $S$ phase arrest and suppression of tumor-related neovascularization and osteolysis through the CXCR4-STAT3 pathway. Int J Oncol 48: 2098-2112, 2016

35. Kashyap D, Tuli HS and Sharma AK: Ursolic acid (UA): A metabolite with promising therapeutic potential. Life Sci 146: 201-213, 2016

36. Meng $\mathrm{Y}$, Lin ZM, Ge N, Zhang DL, Huang $\mathrm{J}$ and Kong $\mathrm{F}$ : Ursolic acid induces apoptosis of prostate cancer cells via the PI3K/Akt/mTOR pathway. Am J Chin Med 43: 1471-1486, 2015.

37. Lu BJ, Wang YQ, Wei XJ, Rong LQ, Wei D, Yan CM, Wang DJ and Sun JY: Expression of WNT-5a and ROR2 correlates with disease severity in osteosarcoma. Mol Med Rep 5: 1033-1036, 2012.

38. Park JH, Kwon HY, Sohn EJ, Kim KA, Kim B, Jeong SJ, Song JH, Koo JS and Kim SH: Inhibition of Wnt/ $\beta$-catenin signaling mediates ursolic acid-induced apoptosis in PC-3 prostate cancer cells. Pharmacol Rep 65: 1366-1374, 2013.
39. Li J, Liang $X$ and Yang X: Ursolic acid inhibits growth and induces apoptosis in gemcitabine-resistant human pancreatic cancer via the JNK and PI3K/Akt/NF- $\mathrm{BB}$ pathways. Oncol Rep 28: 501-510, 2012.

40. Kahn M: Can we safely target the WNT pathway? Nat Rev Drug Discov 13: 513-532, 2014.

41. Reya T and Clevers H: Wnt signalling in stem cells and cancer. Nature 434: 843-850, 2005

42. Hsieh HY, Shen CH, Lin R-I, Feng YM, Huang SY, Wang YH, Wu SF, Hsu CD and Chan MW: Cyproheptadine exhibits antitumor activity in urothelial carcinoma cells by targeting GSK $3 \beta$ to suppress mTOR and $\beta$-catenin signaling pathways. Cancer Lett 370: 56-65, 2016.

43. Vilchez V, Turcios L, Zaytseva Y, Stewart R, Lee EY, Maynard E, Shah MB, Daily MF, Tzeng CW, Davenport D, et al: Cancer stem cell marker expression alone and in combination with microvascular invasion predicts poor prognosis in patients undergoing transplantation for hepatocellular carcinoma. Am J Surg 212: 238-245, 2016.

44. Haydon RC, Deyrup A, Ishikawa A, Heck R, Jiang W, Zhou L, Feng T, King D, Cheng H, Breyer B, et al: Cytoplasmic and/or nuclear accumulation of the beta-catenin protein is a frequent event in human osteosarcoma. Int J Cancer 102: 338-342, 2002.

45. Wang WG, Chen SJ, He JS, Li JS and Zang XF: The tumor suppressive role of RASSF1A in osteosarcoma through the Wnt signaling pathway. Tumour Biol 37: 8869-8877, 2016.

46. Hasty P and Christy BA: p53 as an intervention target for cancer and aging. Pathobiol Aging Age Relat Dis 3: 3, 2013.

47. Bansal N, Kadamb R, Mittal S, Vig L, Sharma R, Dwarakanath BS and Saluja D: Tumor suppressor protein p53 recruits human Sin3B/HDAC1 complex for down-regulation of its target promoters in response to genotoxic stress. PLoS One 6: e26156, 2011.

48. Nam H and Kim M-M: Ursolic acid induces apoptosis of SW480 cells via p53 activation. Food Chem Toxicol 62: 579-583, 2013.

49. Levina E, Oren M and Ben-Ze'ev A: Downregulation of beta-catenin by p53 involves changes in the rate of beta-catenin phosphorylation and Axin dynamics. Oncogene 23: 4444-4453, 2004.

50. Mishra R: Glycogen synthase kinase 3 beta: Can it be a target for oral cancer. Mol Cancer 9: 144, 2010.

51. Fuentes RG, Toume K, Arai MA, Sadhu SK, Ahmed F and Ishibashi M: Scopadulciol, isolated from Scoparia dulcis, induces $\beta$-catenin degradation and overcomes tumor necrosis factor-related apoptosis ligand resistance in AGS human gastric adenocarcinoma cells. J Nat Prod 78: 864-872, 2015.

52. Xie BS, He XX, Ai ZL and Yao SK: Involvement of $\beta$-catenin in matrine-induced autophagy and apoptosis in WB-F344 cells. Mol Med Rep 9: 2547-2553, 2014. 